\title{
Current Frequency Spectral Subtraction and its Contribution to Induction Machines Bearings Condition Monitoring
}

\author{
El Houssin El Bouchikhi, Vincent Choqueuse, Member, IEEE and Mohamed Benbouzid, Senior Member, IEEE
}

\begin{abstract}
Induction machines are widely used in industrial applications. Safety, reliability, efficiency and performance are major concerns that direct the research activities in the field of electrical machines. Even though the induction machine is very reliable, many failures can occur such as bearing faults, air-gap eccentricity and broken rotor bars. The challenge is therefore to detect them at an early stage in order to prevent breakdowns. In particular, stator current-based condition monitoring is an extensively investigated field for cost and maintenance savings. In this context, this paper deals with the assessment of a new stator current-based fault detection approach. Indeed, it is proposed to monitor induction machine bearings by means of stator current spectral subtraction, which is performed using Short Time Fourier Transform or Discrete Wavelet Transform. In addition, it is proposed a diagnostic index based on the subtraction residue energy.

The proposed bearing faults condition monitoring approach is assessed using simulations, issued from a coupled electromagnetic circuits approach-based simulation tool, and experiments on a $0.75-\mathrm{kW}$ induction machine test bed.
\end{abstract}

Index Terms-Induction machines, bearing fault, fault detection, signal processing, spectral subtraction.

\section{NOMENCLATURE}

$\mathcal{S} \mathcal{T} \mathcal{F}$ Short-Time Fourier Transform;

$D W T$ Discrete Wavelet Transform;

$P S D$ Power Spectral Density;

$[.]^{-1} \quad$ Matrix inverse;

$[.]^{T} \quad$ Matrix transpose;

$\left[I_{r}\right] \quad$ Rotor current vector;

$\left[I_{s}\right] \quad$ Stator current vector;

$\left[L_{r r}\right] \quad$ Rotor windings self and mutual inductances;

$\left[L_{r s}\right] \quad$ Mutual inductances between rotor windings and stator ones;

$\left[L_{s r}\right] \quad$ Mutual inductances between stator windings and rotor ones ;

$\left[L_{s s}\right] \quad$ Stator windings self and mutual inductances;

$\left[R_{r}\right] \quad$ Cage resistances matrix;

$\left[R_{s}\right] \quad$ Diagonal matrix of stator phases resistances;

$\left[V_{s}\right] \quad$ Stator voltage vector;

$\frac{d}{d \theta_{m}}[$.$] The derivative with respect to the angular position;$

$\frac{d}{d t}[$.$] \quad The derivative with respect to time;$

E.H. El Bouchikhi, V. Choqueuse and M.E.H. Benbouzid are with the University of Brest, EA 4325 LBMS, Rue de Kergoat, CS 93837, 29238 Brest Cedex 03, France (e-mail: El-Houssin.Elbouchikhi@univ-brest.fr, Vincent.Choqueuse@univ-brest.fr, Mohamed.Benbouzid@univ-brest.fr).

This work was supported by Brest Métropole Océane (BMO).

$\begin{array}{ll}J & \text { Rotating masses inertia; } \\ \Gamma_{C} & \text { Load torque; } \\ \Omega & \text { Rotor mechanical speed; } \\ \theta_{m} & \text { rotor angular position; } \\ f & \text { Viscous friction coefficient; } \\ f_{s} & \text { Shaft rotation frequency; } \\ f_{b d} & \text { Bearing ball fault frequency; } \\ f_{c} & \text { Bearing cage fault frequency; } \\ f_{i d} & \text { Bearing inner race fault frequency; } \\ f_{o d} & \text { Bearing outer race fault frequency; } \\ D & \text { Bearing pitch diameter; } \\ \alpha & \text { Contact angle; } \\ d & \text { Roller diameter; } \\ n & \text { Roller number. }\end{array}$

\section{INTRODUCTION}

Nowadays, induction machines are widely used in industrial applications. In fact, induction machines are still the most important rotating electric machines in industry mainly because of their low price, ruggedness, efficiency and reliability. Despite its robustness, this machine can be subjected to various failures that can broadly be classified as follows [1]:

- Stator faults; opening or shorting of one or more of a stator phase winding;

- Broken rotor bar or cracked rotor end-rings;

- Static and/or dynamic air-gap irregularities;

- Bent shaft;

- Bearing and gearbox failures.

The distribution of these failures within the machine subassemblies is reported in many reliability survey [2], [3]. Depending on the type and size of the machine, bearing faults distributions among all faults vary from $40 \%$ to $90 \%$ from large to small machines.

Therefore, a permanent condition monitoring of the induction machine is of high interest since it contributes to minimize the downtime and improves its reliability and availability. Early diagnosis of these faults is an extensively investigated field for cost and maintenance savings. Traditionally, the machine state can be supervised using different strategies such as vibration monitoring, temperature measurements, flux monitoring, model and artificial intelligence based techniques [4], [5]. Motor current signature analysis for incipient fault detection has received much attention in recent years [2]. These techniques are based on the use of three-phase currents that are already measured in the drive system for other purposes such as control and protection. 
Previous works have focused on the use of signal processing tools for stator current post-processing in order to detect a characteristic fault frequencies in both stationary (steady-state) and non-stationary (transient, variable speed, load oscillation, etc.) operating conditions. In stationary environment, most studies perform stator current spectral analysis using the periodogram and its extensions based on the Fourier Transform [1], [6]-[8]. In order to improve the frequency resolution many high resolution techniques have been used such as the MUSIC algorithm [9], [10]. In non-stationary conditions, timefrequency [11]-[13] and time scale [14] techniques were proposed. Although these techniques lead to good representations, they require a feature extraction and a classification steps in order to distinguish a faulty machine from a healthy one and afterwards measure fault severity.

This paper proposes then a fault detection technique that takes into account some of the above discussed aspects [15]. The proposed technique is based on stator current frequency spectral subtraction. More precisely, the proposed approach is based on the $\mathcal{S T} \mathcal{F} \mathcal{T}$ and allows to directly derive a fault criterion. The fault criterion is of high interest since it conveys the information about the presence of the fault and its severity.

The major contributions of this paper are:

- An intuitive stator current-based fault detection approach.

- A reliable and robust fault criteria for bearing faults detection.

It is organized as follows: The proposed technique is presented in section II. In section III, a short overview of bearing fault types and their effects on induction machine stator current is given. Then, the performances of the proposed approach on simulated data, issued from a coupled electromagnetic circuits approach-based simulation tool, are discussed. Finally, experimental results for several bearing faults are reported in section IV to validate the feasibility of the STFT-based spectral subtraction, which is compared with DWT-based spectral subtraction. Section V concludes this paper and gives some prospects for further investigations.

\section{SPectral Subtraction}

\section{A. Fault Detection Algorithm}

Spectral subtraction is broadly used in audio data processing in order to remove acoustic noise and for speech enhancement [16]-[18]. Up to now, for fault detection, the spectral subtraction was only used as a denoising method. This preprocessing step allows to improve robustness against noise of failure indicators in electrical drives [19], [20]. Afterwards, advanced signal processing techniques are used to detect electrical machine abnormal operating conditions. Figure 1 shows flowcharts illustrating the main differences between the classical technique [20] (Fig. 1(a)) and the proposed one (Fig. 1(b)). In fact, in this paper, we propose to use spectral subtraction as the main tool for induction machines fault diagnosis. In particular, it is used for bearing faults detection using stator current. The proposed technique is well-suited for steady-state and constant speed induction machine operating conditions. It is only applied on stationary signals which means time independent frequency content. In this context, the proposed strategy allows the fault effect extraction from the stator current by subtracting the PSD of the healthy machine from the faulty machine one for each time step.

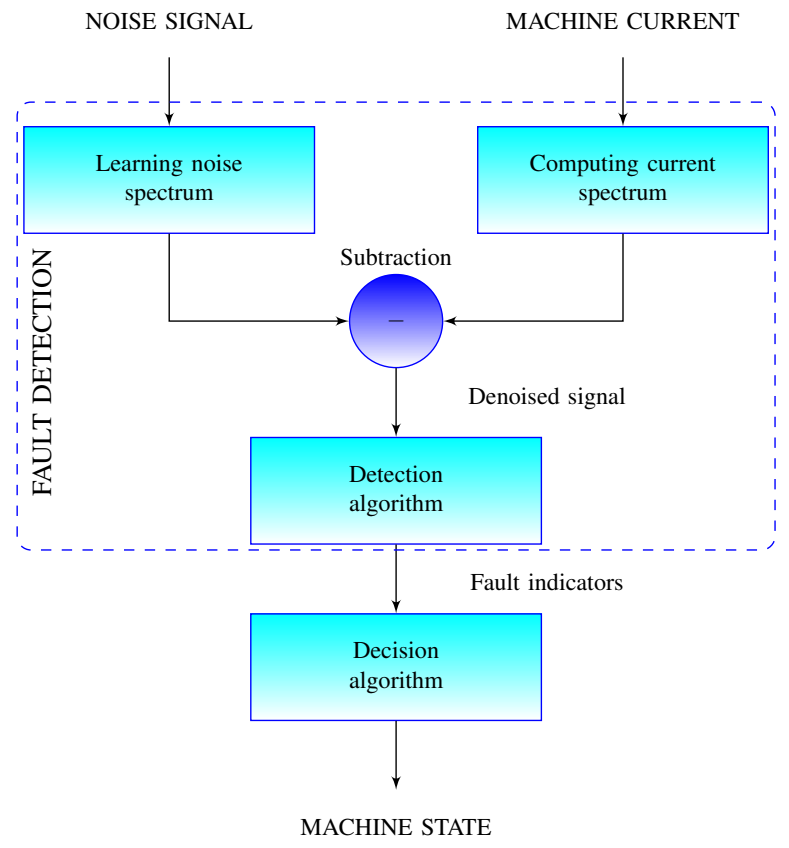

(a) Spectral subtraction for denoising aims.

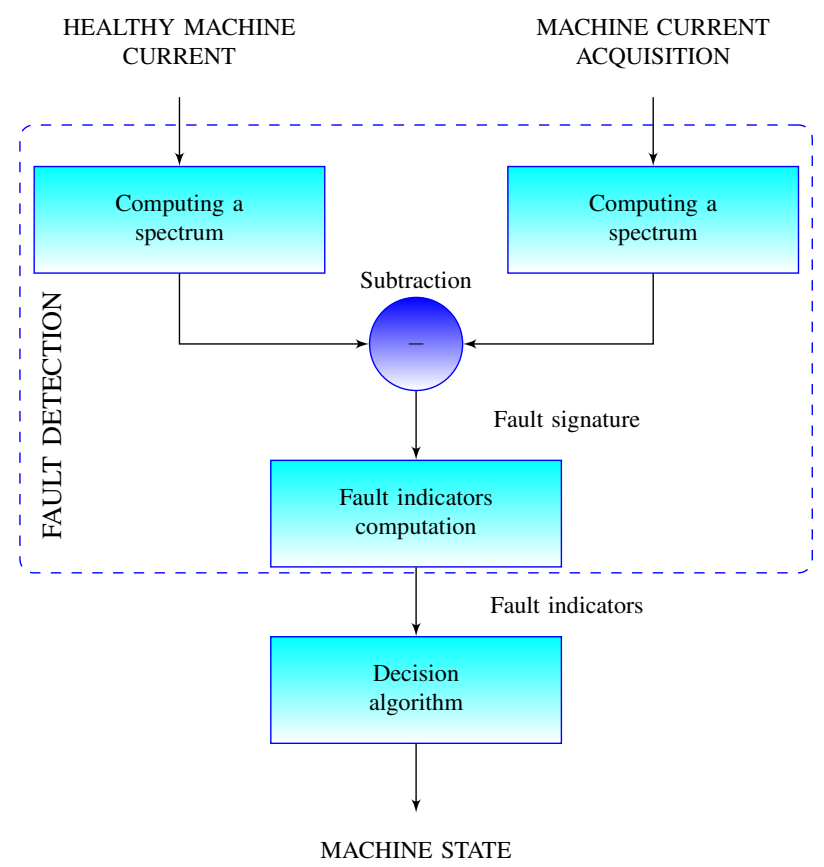

(b) The proposed approach.

Fig. 1. Spectral subtraction flowchart for fault detection approach.

The proposed technique is based on the following steps:

1) Spectral estimation of the healthy signal $x_{h}[n]$ (baseline data) based on the $(\mathcal{S T} \mathcal{F} \mathcal{T})$. The $\mathcal{S} \mathcal{T} \mathcal{F} \mathcal{T}$ of $x_{h}[n]$ is 


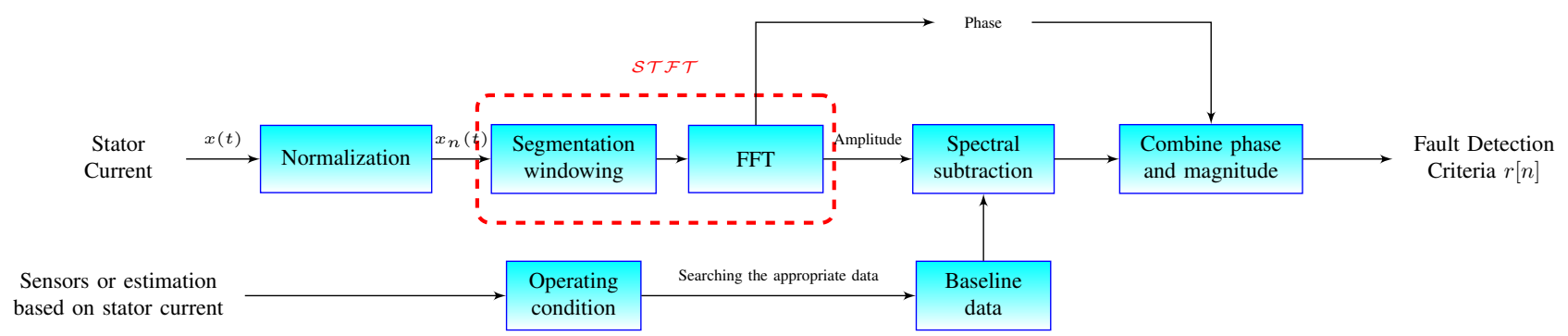

Fig. 2 . Block diagram of the proposed FFT-based spectral subtraction faults detection algorithm.

defined as

$$
X_{h}(m, \omega)=\sum_{n=0}^{N-1} x_{h}[n] w[n-m] e^{-j \omega n}
$$

where $w[n]$ is the window function and $N$ is the number of samples. $m \in \Omega$ corresponds to the time index.

Finally, the spectrum of the healthy signal is computed by averaging the $\mathcal{S} \mathcal{T} \mathcal{F} \mathcal{T}$ with respect to time i.e.(2).

$$
\mu(\omega)=\frac{1}{|\Omega|} \sum_{m \in \Omega}\left|X_{h}(m, \omega)\right|
$$

where $|\Omega|$ denotes the cardinal of the set $\Omega$. This first step is equivalent to the computation of the Welch periodogram [21].

2) Spectral estimation of the supervised machine stator current signal $x_{s}[n]$ using $\mathcal{S} \mathcal{T} \mathcal{F} \mathcal{T}$ (3). The $\mathcal{S} \mathcal{T} \mathcal{F} \mathcal{T}$ of $x_{s}[n]$ is defined as

$$
X_{s}(m, \omega)=\sum_{n=0}^{M-1} x_{s}[n] w[n-m] e^{-j \omega n}
$$

where $w[n]$ has been defined previously and $M$ is the number of samples.

3) Subtraction of the current spectrum of the healthy case from the monitored machine current spectrum at each time $m(4)$;

$$
R(m, \omega)=|| X_{s}(m, \omega)|-\mu(\omega)| e^{\varphi(m, \omega)} \forall m
$$

where $\varphi(m, \omega)=\angle\left(X_{h}(m, \omega)\right)$ and $\angle$ is the angle of the complex number $X_{h}$.

4) Performing the inverse $\mathcal{S} \mathcal{T} \mathcal{F} \mathcal{T}$ to reconstruct the temporal signal $r[n]$ from $R(m, \omega)$ with the Overlap and Add algorithm [22].

5) Computation of the fault indicator.

The spectral subtraction for fault detection is an easy way to extract the fault effect on the stator current. Figure 2 shows then the proposed FFT-based spectral subtraction faults detection algorithm. It clearly illustrates the importance of the operating condition measurement in order to chose the appropriate healthy state condition signal from the database. Ones the healthy state signal is obtained, it is subtracted from the acquired signal in order to diagnose the machine condition. Furthermore, the proposed approach is simple to implement since it is based on the Fourier transform which makes it very attractive for industrial applications. In fact, most DSP-boards include functions for DFT computation. Moreover, the DFT can be efficiently computed using the FFT.

The next subsection deals with the criteria chosen as fault indicator.

\section{B. Fault Detection Criteria}

For an automatic fault detection, we propose two criteria based on the results of the stator current spectral subtraction. These criteria are the fault signature energy $\mathcal{E}$ and the fault signature energy to healthy case energy ratio $\mathcal{R}$.

$$
\left\{\begin{array}{l}
\mathcal{E}=\frac{1}{N} \sum_{n=0}^{N-1}|r[n]|^{2} \\
\mathcal{R}=\frac{\sum_{n=0}^{N-1}|r[n]|^{2}}{\sum_{n=0}^{N-1}\left|x_{h}[n]\right|^{2}}
\end{array}\right.
$$

In addition, to highlight the machine healthy state, the above criteria have also been used to estimate the fault severity degree.

Figure 3 summarizes the proposed fault severity estimation algorithm.

\section{Simulation Results}

This section reports on the performance of the proposed approach on simulated data. Simulation were performed using a coupled electromagnetic circuits induction machine model. In particular, eccentricity fault introduced by bearing failures have been simulated and stator current signal has been sampled and processed according to the above presented algorithm.

\section{A. Coupled Electromagnetic Circuits Machine Modeling Briefly}

The coupled electromagnetic circuits approach combined with the arbitrary reference frames theory is the theoretical groundwork for modeling induction machines [24]. An induction machine is considered as a highly symmetrical electromagnetic system. Any fault will therefore induce a certain degree of asymmetry [25]. In this context, a MatlabSimulnik ${ }^{\circledR}$-based tool of faulty induction machines has been developed to generate a fault database and therefore allow testing different stator current-based fault detection technique [26].

In this modeling context, the representation of an induction machine with a cage rotor is fundamentally the same as one 


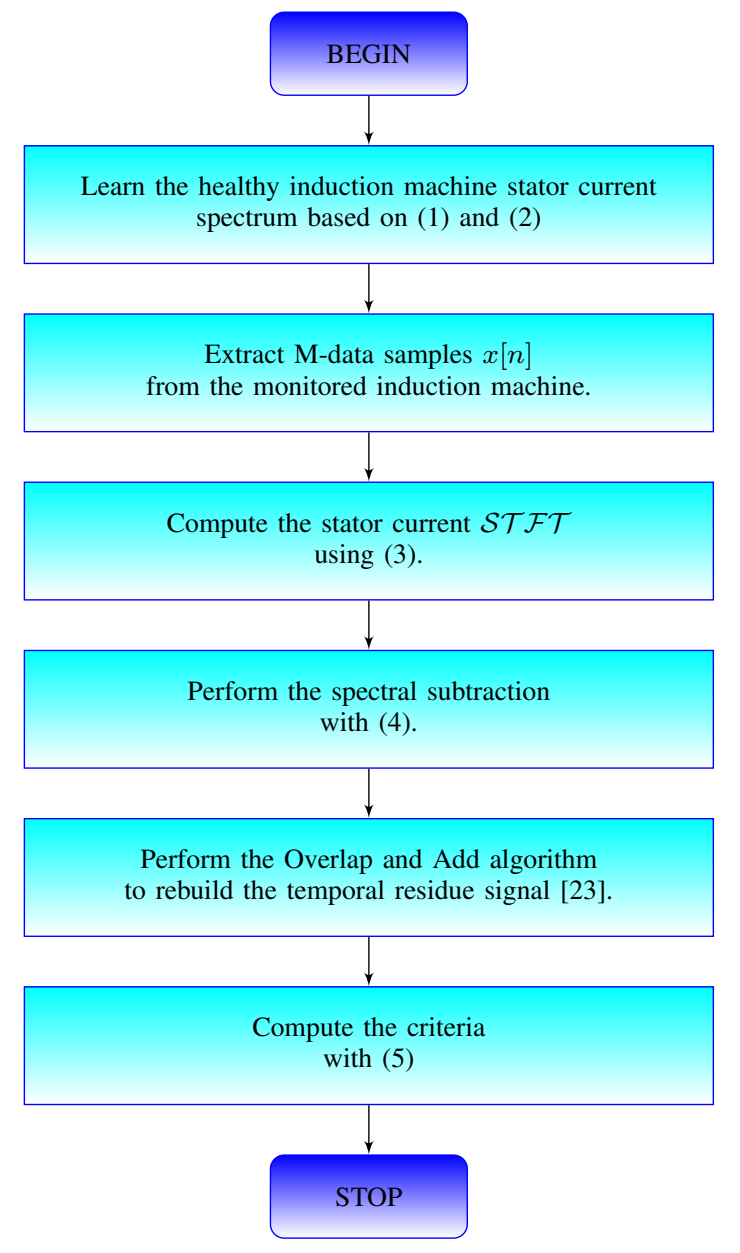

Fig. 3 . Spectral subtraction-based fault severity criteria algorithm.

with a phase wound rotor, where it is assumed that the cage rotor can be replaced by a set of mutually coupled loops as shown by Fig. 4.

The dealt with approach is based on the induction machine analytical models. Inductances are calculated from the actual geometry and winding layout of the machine.

The induction machine electrical and mechanical equation system is given by (6).

$$
\left\{\begin{array}{l}
\frac{d}{d t}[I]=-[L]^{-1}\left([R]+\Omega \frac{d}{d \theta_{m}}[L]\right)[I]+[L]^{-1}[V] \\
\frac{d}{d t} \Omega=\frac{1}{2 J}[I]^{T}\left(\frac{d}{d \theta_{m}}[L]\right)[I]-\frac{f}{J} \Omega-\frac{1}{J} \Gamma_{C} \\
\frac{d}{d t} \theta_{m}=\Omega
\end{array}\right.
$$

where:

$$
\begin{array}{cc}
{[V]=\left[\begin{array}{c}
{\left[V_{s}\right]} \\
{[0]}
\end{array}\right]} & {[I]=\left[\begin{array}{l}
{\left[I_{s}\right]} \\
{\left[I_{r}\right]}
\end{array}\right]} \\
{[R]=\left[\begin{array}{cc}
{\left[R_{s}\right]} & {[0]} \\
{[0]} & \left.\left[R_{r}\right]\right]
\end{array}\right]} & {[L]=\left[\begin{array}{cc}
{\left[L_{s s}\right]} & {\left[L_{s r}\right]} \\
{\left[L_{r s}\right]} & {\left[L_{r r}\right]}
\end{array}\right]}
\end{array}
$$

All the relevant inductances matrices $[L]$ are calculated using the winding function method [27].

\section{B. Bearing Faults Detection}

1) Bearing Fault Impact on Induction Machine Stator Current: Vibration analysis is one of the most extended condition

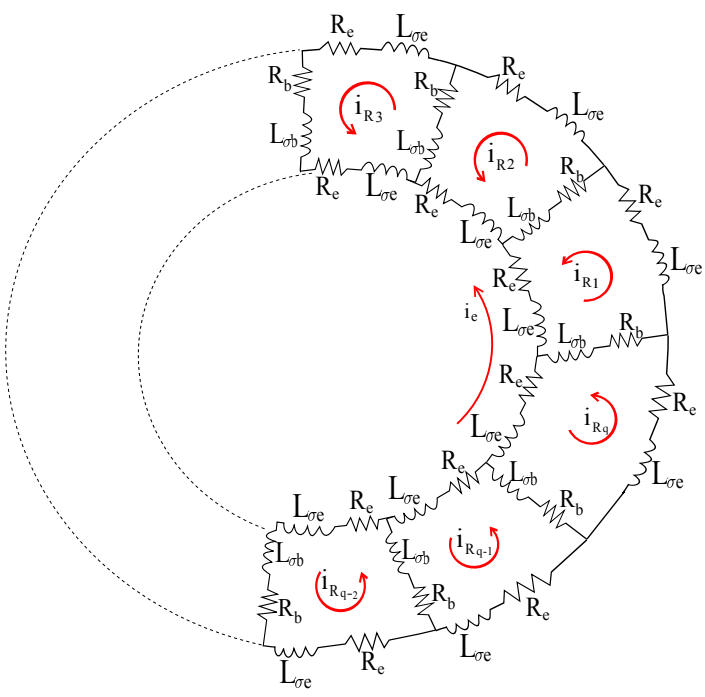

Fig. 4 . Equivalent circuit of a cage rotor showing rotor loop and circulating end-ring current.

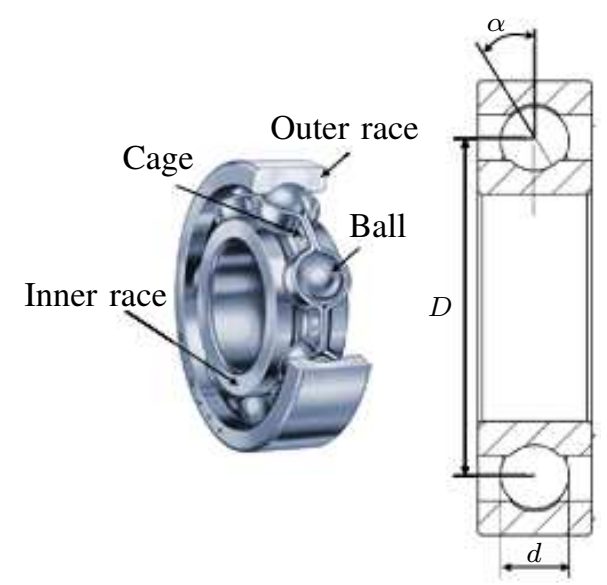

Fig. 5 . Bearing structure with main dimensions.

monitoring techniques for bearing fault diagnosis. Bearings defects have been typically categorized as distributed or local. Local defects cause periodic impulses in vibration signals. Amplitude and frequency of such impulses are determined by shaft rotational speed, fault location, and bearing dimensions (Fig. 5). The frequencies of these impulses are given in (7).

$$
\left\{\begin{array}{l}
f_{c}=\frac{f_{s}}{2}\left(1-\frac{d}{D} \cos (\alpha)\right) \\
f_{b d}=\frac{D}{d} f_{s}\left(1-\frac{d^{2}}{D^{2}} \cos ^{2}(\alpha)\right) \\
f_{i d}=\frac{n f_{s}}{2}\left(1-\frac{d}{D} \cos (\alpha)\right) \\
f_{o d}=\frac{n f_{s}}{2 d}\left(1-\frac{d}{D} \cos (\alpha)\right)
\end{array}\right.
$$

In [28], [29], it has been demonstrated that the characteristic bearing fault frequencies in vibration can be reflected on stator currents. Since ball bearings support the rotor, any bearing defect will produce a radial motion between the rotor and the stator of the machine (air-gap eccentricity) which may lead to anomalies in the air-gap flux density. As the stator current 
for a given phase is linked to flux density, the stator current is affected as well by the bearing defect. The relationship between vibration frequencies and current frequencies for bearing faults can be described by (8). Therefore, by means of (8), it is possible to analyze the specific fault sub-harmonics in order to find abnormalities in their amplitude values.

$$
f_{b n g}=\left|f_{s} \mp k f_{d}\right|
$$

where $k=1,2,3, \ldots$ and $f_{d}$ is one of the characteristic vibration frequencies given above.

It is well established that for bearing single-point defects, the characteristic stator current fault frequencies are good fault indicators [29], [30]. This model has been applied in several works dealing with bearing faults detection. It has also been demonstrated that these bearings faults have an effect over the machine eccentricity and/or load variations. Therefore, The analysis of stator current fundamental sidebands, in order to detect eccentricity or load variations, can also be useful for bearing diagnosis. The above bearing faults model components are analyzed using spectral analysis in [31]. In [32], [33] timefrequency and time-scale methods are used to identify bearing faults by analyzing stator current based on the same model.

In this section, the approach in [29] has been adopted to model bearing failure effects on induction machine stator current. In particular, static and mixed eccentricities were used to emulate bearing faults in the induction machine.

Stator current signals have been simulated using coupled electromagnetic approach during 2 seconds at $10 \mathrm{kHz}$ sampling rate with $10 \%$ static and mixed eccentricities. Simulation results are given in Fig. 6. It is obvious that static and mixed eccentricities (modeling the bearing fault) introduce sidebands on the stator current. It should be stressed that the discrimination of the defected component requires explicit knowledge of the bearing geometry.

2) Static eccentricity detection using spectral subtraction: In this case, Fig. 7(a) shows the induction machine stator current for healthy and faulty conditions. Figure 7(b) illustrates then the spectral subtraction results. It is therefore obvious that the simulated fault is clearly highlighted by the proposed approach. Moreover, the achieved results prove the effectiveness of monitoring the amplitudes of fundamental sidebands for fault detection in induction machine.

3) Mixed eccentricity detection using spectral subtraction: The same conclusions are drawn in this second case with Figs. 7(c) and 7(d), respectively illustrating the induction machine stator current and the spectral subtraction result.

To summarize the simulation results, it should be mentioned that the proposed spectral subtraction-based fault detection approach is effective in terms of fault impact extraction from the stator current. Indeed, this impact is obvious and clearly highlights the occurrence of a fault within the induction machine (Figs. 7(b) and 7(d)).

\section{EXPERIMENTAL TESTS}

A conventional $0.75 \mathrm{~kW}$ induction machine drive test rig is used in order to test the proposed spectral subtraction-based fault detection approach (Fig. 8).

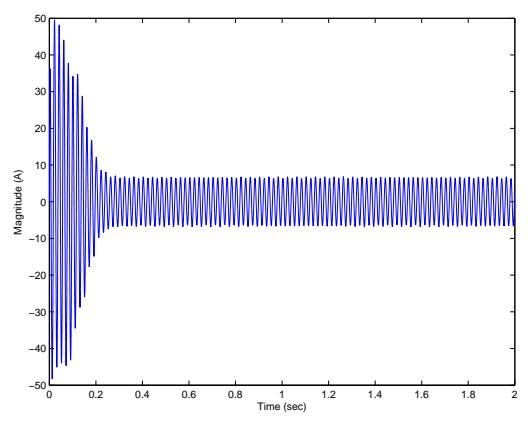

(a) Induction machine stator current with static eccentricity.

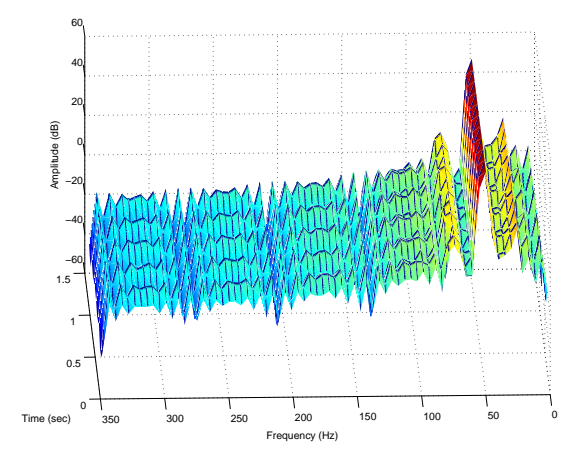

(b) Faulty induction machine stator current spectrogram.

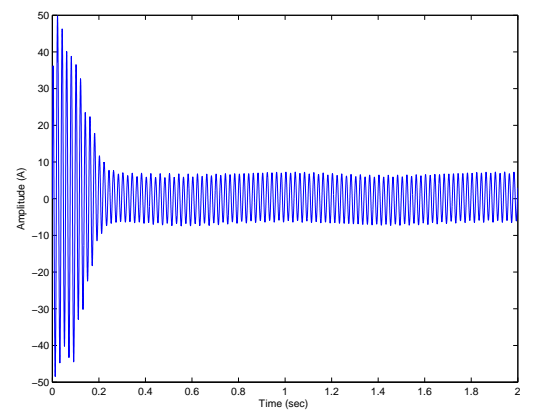

(c) Induction machine stator current with mixed eccentricity.

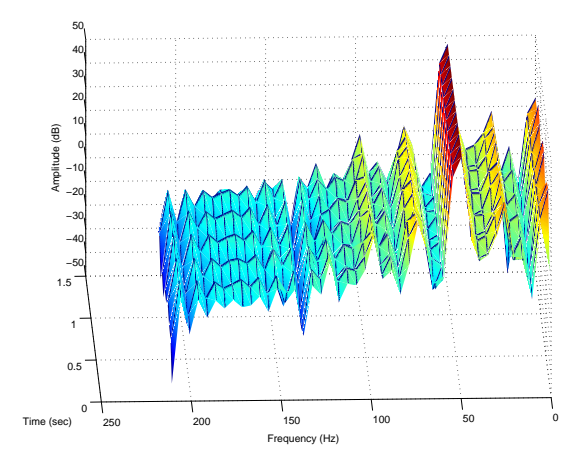

(d) Faulty induction machine stator current spectrogram.

Fig. 6 . Faulty induction machine simulation signals.

\section{A. Test Rig}

The test rig mechanical part (Fig. 8(a)) is composed by a synchronous and an induction machine. The induction machine is fed by the synchronous generator in order to eliminate time 


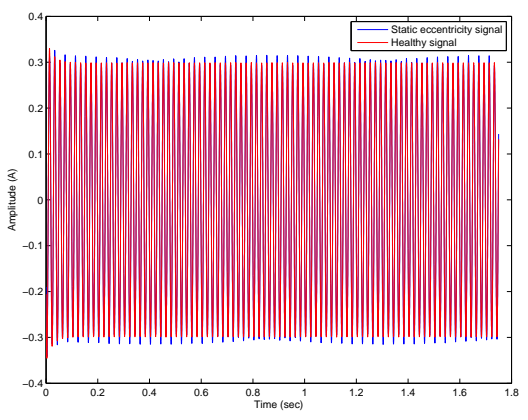

(a) Stator currents for healthy and static eccentricity failure.

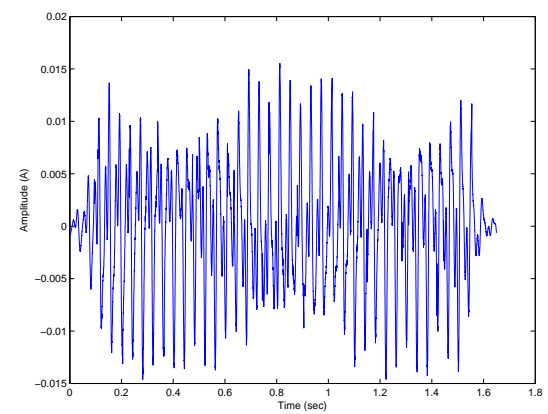

(b) Static eccentricity effect on stator current.

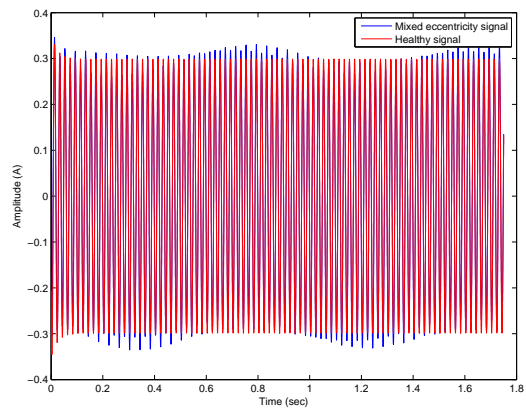

(c) Stator currents for healthy and mixed eccentricity failure.

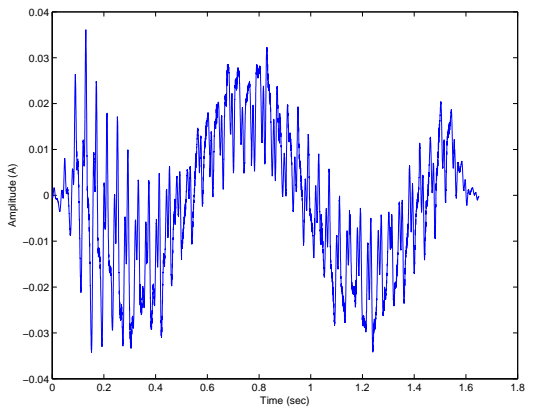

(d) Dynamic eccentricity effect on stator current.

Fig. 7 . Spectral subtraction on simulation stator currents.

harmonics. Indeed, this will automatically eliminate supply harmonics and therefore allow focusing only on bearing faults effect on the stator current.

The induction machine has two 6204.2ZR type bearings (single row and deep groove ball bearings) with the following parameters: outside diameter is $47 \mathrm{~mm}$, inside one is $20 \mathrm{~mm}$, and pitch diameter $D=31.85 \mathrm{~mm}$. A bearing has 8 balls $(n=8)$ with an approximate diameter of $\mathrm{d}$ of $12 \mathrm{~mm}$ and a contact angle of $\alpha=0$.

Bearing faults are obtained by simply drilling holes in different parts (Fig. 9) [34].

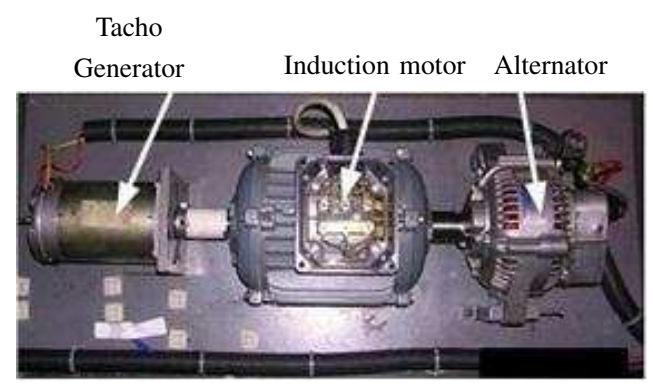

(a) Mechanical part.

\section{Connectors to}

the mechanical part Current transformers Load(bulbs)

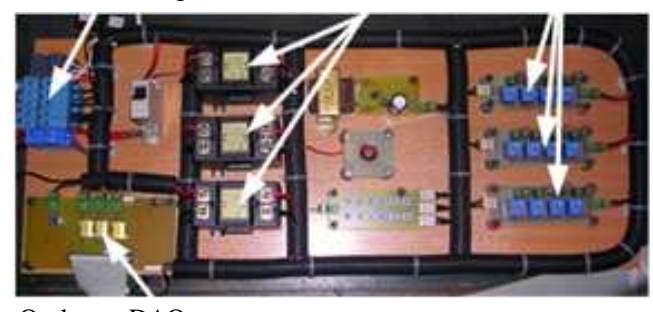

Outlet to DAQ

card and PC

(b) Electrical part.

Fig. 8 . Test rig.

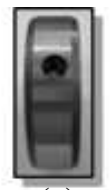

(a)

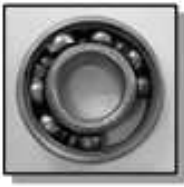

(c)

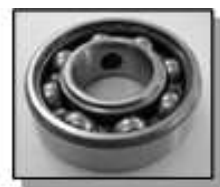

(b)

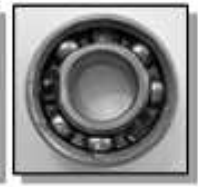

(d)
Fig. 9 . Artificially deteriorated bearing: (a) outer race deterioration, (b) inner race deterioration, (c) cage deterioration, (d) ball deterioration.

\section{B. Experimental Results Analysis}

Experimental tests focus on single-point defects which are localized ones and can be classified according to the following affected elements: outer raceway, inner raceway, ball, and bearing cage (Fig. 9) [35].

An accurate fault detection is questionable without investigating the robustness against load variation and the relationship between the criteria and faults level. For that purpose, the 
Table 1 . Fault detection criteria for ball bearing fault

\begin{tabular}{|c|c||c|c||c|}
\hline Criterion & $\mathcal{R}$ & $\left(10^{-4}\right)$ & $\mathcal{E}$ & $\left(10^{-4}\right)$ \\
\hline Bearing & Healthy & Faulty & Healthy & Faulty \\
\hline No load & 2.04 & 154 & 1.28 & 99 \\
\hline $100 \mathrm{~W}$ & 7.18 & 142 & 4.23 & 83.9 \\
\hline $200 \mathrm{~W}$ & 3.53 & 143 & 1.71 & 69.4 \\
\hline $300 \mathrm{~W}$ & 1.27 & 102 & 0.423 & 34.6 \\
\hline $400 \mathrm{~W}$ & 0.88 & 64.7 & 0.192 & 14.14 \\
\hline
\end{tabular}

proposed fault detection criteria sensitivity has been evaluated according to load variations.

The measured stator currents are acquired at $10 \mathrm{kHz}$ by data acquisition card. Further signal post-processing is done off-line on a standard desktop PC using Matlab. The following experimental validation is focused on the ball, inner raceway, and cage bearing failures for different load conditions.

1) Ball bearing fault detection: Figures 10 and 11 illustrate the results of the spectral subtraction in the case of a ball bearing fault. These figures show the healthy and faulty stator current, and the resulting fault signature in time domain for an unloaded and loaded induction machine, respectively. This residue is used to compute the criteria in (5).

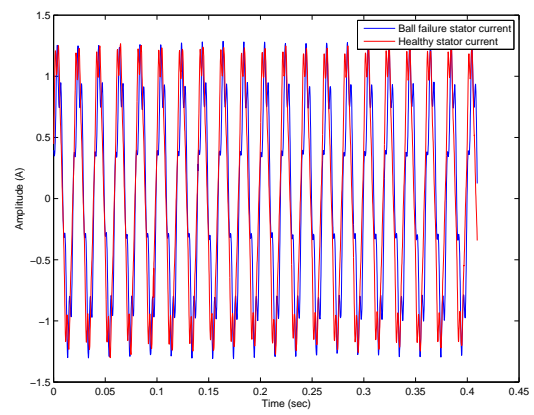

(a) Healthy and bearing failure stator currents.

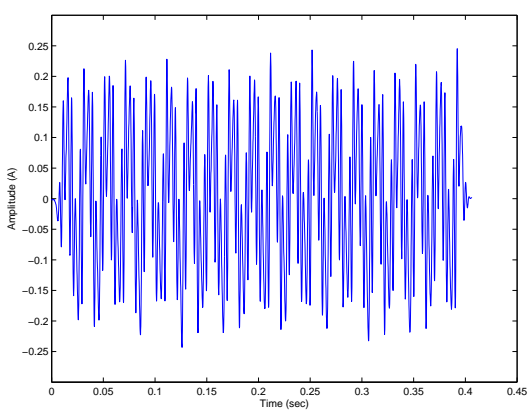

(b) Failure signature.

Fig. 10 . Spectral subtraction on experimental stator currents for an unloaded machine.

Table 1 reports on the criteria values. It depicts the criteria for healthy and faulty induction machine under different load conditions. These results clearly show the appropriateness of the proposed fault detection approach. To confirm this tendency, additional tests have been carried-out to detect other bearing fault types.

2) Experimental results for different bearing faults: Figure 12 shows the variation of the two criteria for different

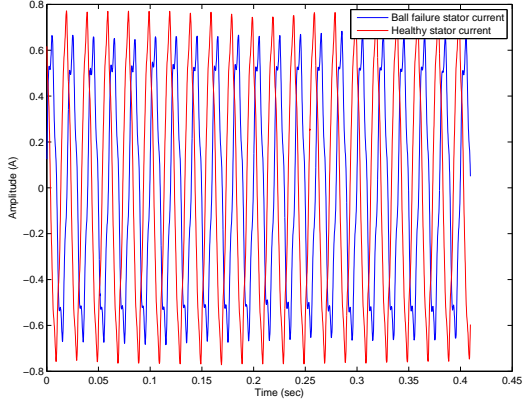

(a) Healthy and bearing failure stator currents.

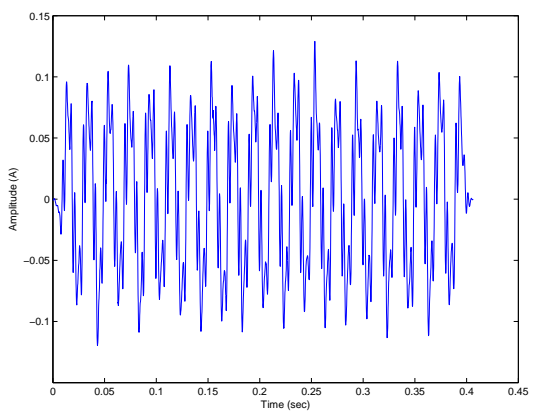

(b) Failure signature.

Fig. 11. Spectral subtraction on experimental stator currents for a $400 W$ loaded machine.

bearing fault; namely inner race, cage, and ball faults.

According to these bar graphs, it can be concluded that spectral subtraction allows diagnosing the induction machine abnormal operating conditions regardless of load conditions. In fact, despite the criteria are load-sensitive, they remain higher compared to a healthy machine even when the load increases. The criteria variation between the faulty and healthy case allows highlighting faulty operating conditions. It is clear that the energy ratio is more suitable for fault detection since it is less load-sensitive.

3) Comparison with DWT-based spectral subtraction: The wavelet transform based spectral subtraction could be performed by introducing some modifications in the abovedescribed algorithm. In fact, the faulty and the database (healthy) stator current signals are first processed in order to remove the phase-shift between the two signals. Afterwards, the wavelet decomposition at level 10 is performed using Daubechies wavelet of order 32 for both signals. Then, the spectral subtraction is performed on the approximation signal and details. The inverse wavelet transform is then used in order to reconstruct the residue signal in the time-domain. Finally, the two criteria proposed within this paper are computed. Figure 13 illustrates the results for different operating conditions.

The same conclusions could be drawn from this bar chart as in the case of the use of $\mathcal{S T} \mathcal{F} \mathcal{T}$. The DWT-based spectral subtraction gives reliable results and allows to discriminate the faulty case from the healthy one since the criteria are higher in the case of faulty machine than in the case of the healthy one. It seems from these results that it is easier 


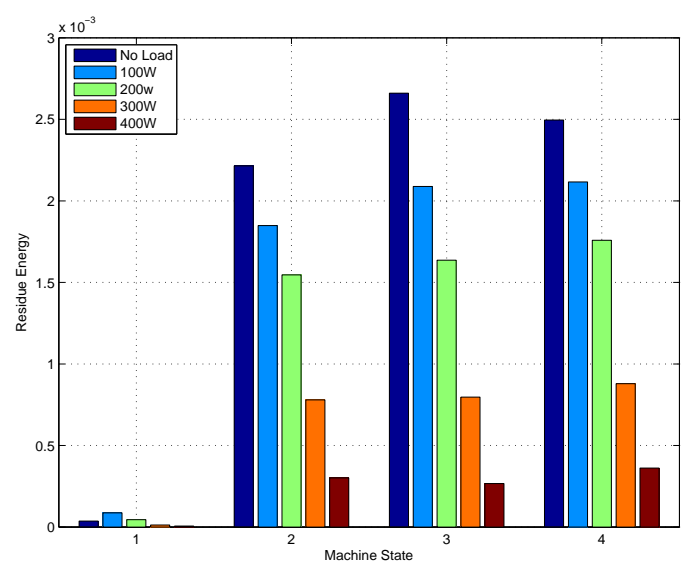

(a) Residue energy.

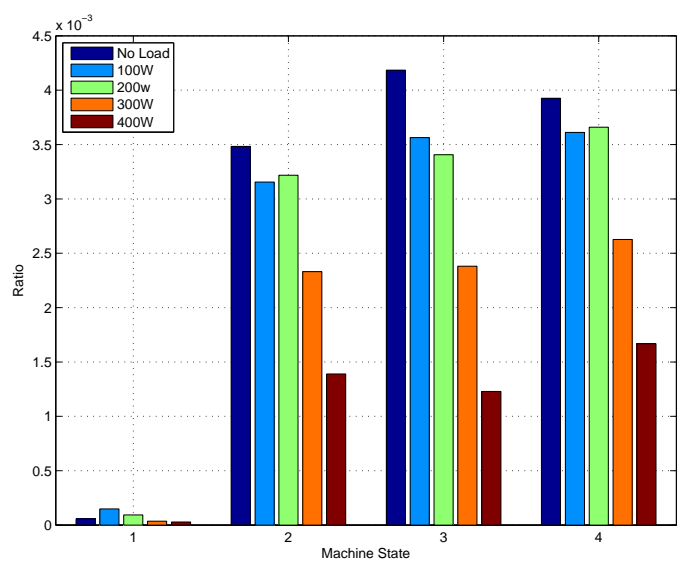

(b) Residue to healthy energy ratio.

Fig. 12 . Fault detection criteria for different load conditions and various faults ( 1 : healthy, 2: inner race, 3: cage, 4: ball).

to discriminate the faulty machine by using the FFT-based spectral subtraction than the DWT-based spectral subtraction. This comparison allows to assert that the induction machine fault detection based on spectral subtraction may be performed using several time-frequency representations such as wavelet transform, Wigner-Ville distribution, Hilbert-Huang transform and many others.

\section{Summary and Discussions}

A simple fault metric has been evaluated here based on the instantaneous amplitudes of the extracted fault frequencies. This metric could be used to indicate a bearing fault at an early stage. Thresholds can be set to determine the severity of the fault and can provide an indication for prognosis purposes.

The spectral subtraction is based on the Fourier transform which means that the technique is limited by the Fourier transform resolution [36]. Despite this limitation, the proposed technique gives good results on simulated and experimental signals. Furthermore, comparison with DWT-based spectral subtraction has been performed. It demonstrates that in both cases the spectral subtraction is a well-suited technique to diagnose abnormalities in the induction machine and especially bearing failures. This comparison proves the appropriateness

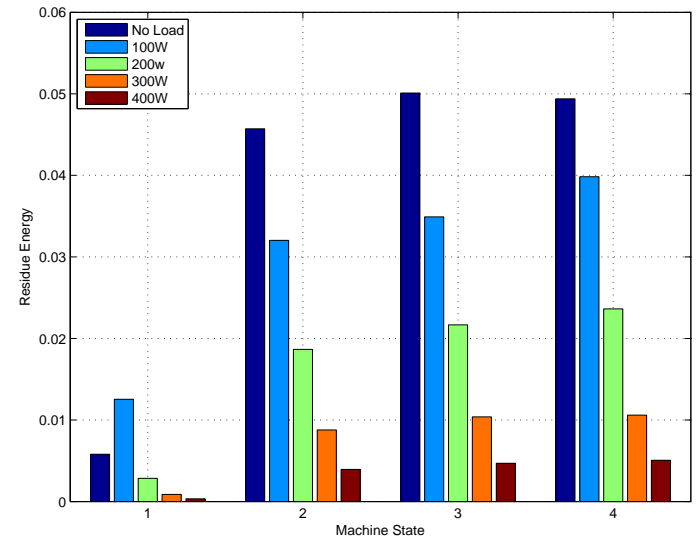

(a) Residue energy.

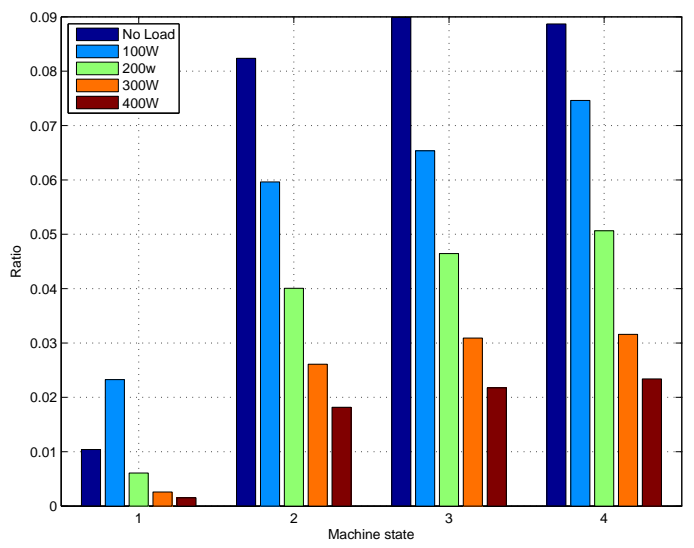

(b) Residue to healthy energy ratio.

Fig. 13 . Fault detection criteria based on discrete wavelet transform for different load conditions and various faults ( 1 : healthy, 2: inner race, 3: cage, 4: ball).

of the spectral subtraction as medium for fault detection in induction machine through stator current analysis.

The general conclusions that can be drawn from these simulation and experimental results are the effectiveness of the proposed fault detection approach. In the case where the stator current frequency content does not abruptly change, the proposed approach is assumed to be a well adapted tool to detect abnormal operating conditions in a non-stationary environment. In this case, a new baseline data should be retrieved and processed.

\section{Conclusion}

This paper dealt with the induction machine bearing faults detection. It has been proposed a new stator current-based fault detection approach. Indeed, it has been suggested to monitor induction machine bearings by means of stator current spectral subtraction. The proposed technique effectiveness has been first confirmed using simulation data issued from a coupled electromagnetic circuits approach-based simulation tool. Afterwards, it has been validated by experiments on a $0.75-\mathrm{kW}$ induction machine drive test bed. Other timefrequency tools could be used to perform spectral subtraction. It may perform better than the spectrogram since they have 
good resolution capabilities in time and frequency domains such as Wigner-Ville distribution and Continuous wavelet transform. Moreover, further investigations are required in order to propose a suited decision algorithm that may allow the automatic detection of a faulty machine using the fault detection strategy studied within this paper.

\section{APPENDIX}

RATED DATA OF THE TESTED INDUCTION MACHINE

$0.75 \mathrm{~kW}, 50 \mathrm{~Hz}, 220 / 380 \mathrm{~V}, 3.4 / 1.95 \mathrm{~A}, 2780 \mathrm{rpm}, p=1$

\section{REFERENCES}

[1] M. E. H. Benbouzid, "A review of induction motors signature analysis as a medium for faults detection," IEEE Trans. Industrial Electronics, vol. 47, no. 5, pp. 984-993, October 2000.

[2] P. Zhang, Y. Du, T. Habetler, and B. Lu, "A survey of condition monitoring and protection methods for medium-voltage induction motors," IEEE Transactions on Industry Applications, vol. 47, no. 1, pp. 34-46, January/February 2011.

[3] A. H. Bonnett and C. Yung, "Increased efficiency versus increased reliability," IEEE Industry Applications Magazine, vol. 14, no. 1, pp. 29-36, January/February 2008.

[4] S. Nandi, H. A. Toliyat, and X. Li, "Condition monitoring and fault diagnosis of electrical motors - a review," IEEE Trans. Energy Conversion, vol. 20, no. 4, pp. 719-729, December 2005.

[5] M. E. H. Benbouzid and G. Kliman, "What stator current processing based technique to use for induction motor rotor faults diagnosis?" IEEE Trans. Energy Conversion, vol. 18, no. 2, pp. 238-244, June 2003.

[6] A. Bellini, F. Filippetti, C. Tassoni, and G. A. Capolino, "Advances in Diagnostic Techniques for Induction Machines," IEEE Transactions on Industrial Electronics, vol. 55, no. 12, pp. 4109-4126, December 2008

[7] G. Didier, E. Ternisien, O. Caspary, and H. Razik, "Fault detection of broken rotor bars in induction motor using a global fault index," IEEE Trans. Industry Applications, vol. 42, no. 1, pp. 79-88, Jan. 2006.

[8] A. Yazidi, H. Henao, G. A. Capolino, M. Artioli, and F. Filippetti, "Improvement of frequency resolution for three-phase induction machine fault diagnosis," in Proceedings of the 2005 IEEE IAS Annual Meeting, Hong Kong (China), October 2005, pp. 20-25.

[9] A. Bellini, A. Yazidi, F. Filippetti, C. Rossi, and G. Capolino, "High frequency resolution techniques for rotor fault detection of induction machines," IEEE Trans. Industrial Electronics, vol. 55, no. 12, pp. 4200 4209, December 2008.

[10] M. Benbouzid, H. Nejjari, R. Beguenane, and M. Vieira, "Induction motor asymmetrical faults detection using advanced signal processing techniques," IEEE Trans. Energy Conversion, vol. 14, no. 2, pp. 147152, June 1999

[11] E. H. El Bouchikhi, V. Choqueuse, M. E. H. Benbouzid, J. Charpentier, and G. Barakat, "A comparative study of time-frequency representations for fault detection in wind turbine," in Proceedings of the 2011 IEEE IECON, Melbourne (Australia), November 2011, pp. 3584-3589.

[12] M. Blodt, J. Regnier, and J. Faucher, "Distinguishing load torque oscillations and eccentricity faults in induction motors using stator current wigner distributions," IEEE Trans. Industry Applications, vol. 45, no. 6, pp. 1991-2000, November/December 2009.

[13] B. Yazici and G. Kliman, "An adaptive statistical time-frequency method for detection of broken bars and bearing faults in motors using stator current," IEEE Trans. Industry Applications, vol. 35, no. 2, pp. 442-452, March/April 1999.

[14] J.Pons-Llinares, J. Antonino-Daviu, M. Riera-Guasp, M. PinedaSanchez, and V. Climente-Alarcon, "Induction motor diagnosis based on a transient current analytic wavelet transform via frequency b-splines," IEEE Trans. Industrial Electronics, vol. 58, no. 5, pp. 1530-1544, May 2011.

[15] E. H. El Bouchikhi, V. Choqueuse, M. E. H. Benbouzid, and J. Charpentier, "Induction machine bearing failures detection using stator current frequency spectral subtraction," in Proceedings of the 2012 IEEE ISIE, Hangzhou (China), May 2012, pp. 1228-1233.
[16] G.Yu, S. Mallat, and E. Bacry, "Audio denoising by time-frequency block thresholding," IEEE Trans. Signal Processing, vol. 56, no. 5, pp. 1830-1839, May 2008.

[17] Y. Ephraim and D. Malah, "Speech enhancement using a minimum mean square short-time spectral amplitude estimator," IEEE Trans. Acoustics, Speech and Signal Processing, vol. ASSP-32, no. 6, pp. 1109-1121, December 1984.

[18] S. Boll, "Suppression of acoustic noise in speech using spectral subtraction," IEEE Trans. Acoustics, Speech and Signal Processing, vol. ASSP-27, no. 2, pp. 113-120, April 1979.

[19] I. Bozchalooi and M. Liang, "A joint resonance frequency estimation and in-band noise reduction method for enhancing the detectability of bearing fault signals," Mechanical Systems and Signal Processing, vol. 22, no. 4, pp. 915-933, May 2008.

[20] J. Dron, F. Boleas, and I. Rasolofondraibe, "Improvement of the sensitivity of the scalar indicators (vrest factor, kurtosis) using a denoising method by spectral subtraction: application to the detection of defects in ball bearings," Journal of Sound and Vibration, vol. 270, no. 1-2, pp. 61-73, February 2004.

[21] S. Kay and S. Marple, "Spectrum analysis - a modern perspective," Proceedings of the IEEE, vol. 69, no. 11, pp. 1380-1419, November 1981.

[22] M. Narasimha, "Modified ovelap-add and overlap-save convolution algorithms for real signals," IEEE Signal Processing Letters, vol. 13 , no. 11 , pp. 669-671, November 2006.

[23] R. E. Crochiere, "A weighted overlap-add method of short-time fourier analysis/synthesis," IEEE Trans. Acoustics Speech, and Signal Processing, vol. ASSP-28, no. 1, pp. 99-102, Feb. 1980.

[24] H. Toliyat and T. Lipo, "Transient analysis of cage induction machines under stator, rotor bar and end ring faults," IEEE Trans. Energy Conversion, vol. 10, no. 2, pp. 241-247, June 1995.

[25] H. Toliyat, M. Arefeen, and A. Parlos, "A method for dynamic simulation of air-gap eccentricity in induction machines," IEEE Trans. Industry Applications, vol. 32, no. 4, pp. 910-918, July/August 1996.

[26] D. Dupont and A. Gautriaud, "Failure modeling in wind and tidal turbine generators: development of simulation tool," University of Brest, Tech. Rep., November 2011.

[27] G. Joksimovic, M. Durovic, J. Penman, and N. Arthur, "Dynamic simulation of dynamic eccentricity in induction machines-winding function approach," IEEE Trans. Energy Conversion, vol. 15, no. 2, pp. 143-148, June 2000.

[28] A. Knight and S. Bertani, "Mechanical fault detection in a medium-sized induction motor using stator current monitoring," IEEE Trans. Energy Conversion, vol. 29, no. 4, pp. 753-760, December 2005.

[29] R. Schoen, T. Habetler, F. Kamran, and R. Bartheld, "Motor bearing damage detection using stator current monitoring," IEEE Trans. Industry Applications, vol. 31, no. 6, pp. 1274-1279, November/December 1995.

[30] M. Blodt, P. Granjon, B. Raison, and G. Rostaing, "Models for bearing damage detection in induction motors using stator monitoring," IEEE Trans. Industrial Electronics, vol. 55, no. 4, pp. 1813-1822, Avril 2008.

[31] J. Stack, T. G. Habetler, and R. G. Harley, "Bearing fault detection via autoregressive stator current modeling," IEEE Trans. Industry Applications, vol. 40, no. 3, pp. 740-747, May/June 2004.

[32] A. Lebaroud and G. Clerc, "Classification of induction machine faults by optimal time-frequency representations," IEEE Trans. Industrial Electronics, vol. 55, no. 12, pp. 4290-4298, December 2010.

[33] L. Eren, K. Teotrakool, and M. Devaney, "Bearing fault detection via wavelet packet decomposition with spectral post processing," in Proceedings of the 2007 IEEE IMTC, Warsaw (Poland), May 2007, pp. $1-4$.

[34] Z. Obeid, S. Poignant, J. Regnier, and P. Maussion, "Stator current based indicators for bearing fault detection in synchronous machine by statistical frequency selection," in Proceedings of the 2011 IEEE IECON 2011, Melbourne, Australia, Nov. 2011, pp. 2036-2041.

[35] J. Stack, T. G. Habetler, and R. G. Harley, "Fault classification and fault signature production for rolling element bearings in electric machines," IEEE Trans. on Industry Applications, vol. 40, no. 3, pp. 735-739, May/Jun. 2004

[36] L. Cohen, Time-Frequency Analysis. Englewood Cliffs, NJ: PrenticeHall, 1995. 


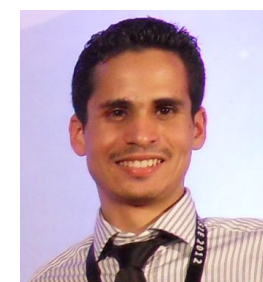

erating conditions.

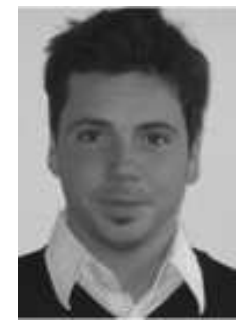

MIMO systems.
El Houssin El Bouchikhi was born in Khemisset, Morocco, in 1987. He received the Dipl.-Ing. and the M.Sc. degrees in automatic and electrical engineering, from the National Polytechnic Institute of Toulouse (INP-ENSEEIHT), Toulouse, France, in 2010. He is currently working toward the Ph.D. degree on offshore wind and marine current turbines condition monitoring with the University of Brest, Brest, France. His current research interests are electrical machines fault detection and diagnosis through electrical quantities, especially in non-stationary op-

Vincent Choqueuse (M'08) was born in Brest, France, in 1981. He received the Dipl.-Ing. and the M.Sc. degrees in 2004 and 2005, respectively, from Troyes University of Technology, Troyes, France, and the Ph.D. degree in 2008 from the University of Brest, Brest, France. Since September 2009, he has been an Associate Professor with the Institut Universitaire de Technologie of Brest, University of Brest, Brest, France, and a member of the LBMS Lab (EA 4325). His research interests focus on signal processing and statistics for diagnosis and

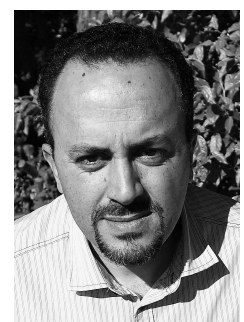

Mohamed El Hachemi Benbouzid (S'92-M'95SM'98) was born in Batna, Algeria, in 1968. He received the B.Sc. degree in electrical engineering from the University of Batna, Batna, Algeria, in 1990, the M.Sc. and Ph.D. degrees in electrical and computer engineering from the National Polytechnic Institute of Grenoble, Grenoble, France, in 1991 and 1994, respectively, and the Habilitation à Diriger des Recherches degree from the University of Picardie "Jules Verne," Amiens, France, in 2000.

After receiving the Ph.D. degree, he joined the Professional Institute of Amiens, University of Picardie "Jules Verne," where he was an Associate Professor of electrical and computer engineering. Since September 2004, he has been with the Institut Universitaire de Technologie of Brest, University of Brest, Brest, France, where he is a Professor of electrical engineering. His main research interests and experience include analysis, design, and control of electric machines, variable-speed drives for traction, propulsion, and renewable energy applications, and fault diagnosis of electric machines.

Prof. Benbouzid is a Senior Member of the IEEE Power Engineering, Industrial Electronics, Industry Applications, Power Electronics, and Vehicular Technology Societies. He is an Associate Editor of the IEEE TRANSACTIONS ON ENERGY CONVERSION, the IEEE TRANSACTIONS ON INDUSTRIAL ELECTRONICS, the IEEE TRANSACTIONS ON SUSTAINABLE ENERGY, and the IEEE TRANSACTIONS ON VEHICULAR TECHNOLOGY. He was an Associate Editor of the IEEE/ASME TRANSACTIONS ON MECHATRONICS from 2006 to 2009. 